\title{
Las ediciones del Facundo
}

Carmiento, poco después de la aparición del Facundo, se refirió en tono humorístico al nacimiento del folletín en el periodismo chileno. "Sabe el público -escribía en El Progreso de Santiago- que gemimos bajo dos acusaciones horribles: la de haber hecho conocer a Michelet, Cousin y Jouffroi y lo que es más horrible, la de haber introducido en los diarios, folletines". Luego habla de "la lepra del folletín (que ha ganado ya todos los diarios") y nos hace saber que El Mercuria -implacable enemigo - ha publicado ya Los misterios de Londres, los de París y El jecdio errante. $\mathrm{Y}$ en el mismo tono de burla, pregunta: " $\mathrm{Y}$ no hay castigo para los redactores de El Progreso?"

Como sabemos, también el Facundo fue folletín en el diatio donde empezó a colaborar desde 1842. Y allí también poco antes había dado su Aldao. El carácter episódico y la conveniente necesidad de estimular el interés del lector como se lograba con las novelas de Dumas, explican no poco del constante apoyo en la expresión exclamativa (BarrancaYaco!!!), interrogaciones retóticas, puntos suspensivos, y todas las formas del diálogo vivo que importan actualización dramática de un episodio. Cuando aparezca reunido en volumen en el mes de julio, el crítico de su diario escribirá: "Nuestra imprenta acaba de dar a luz esta interesante obrita, que El Progreso comenzó en su folletín con tanto gusto del público". En efecto, el día 2 de mayo de 1845 , en el número 769 y debajo de un editorial sobre la iglesia y el estado, el lector comenzó a leer: "Folletín del Progreso/Facundo". Un epígrafe en francés tomado de Villemain y referido a la historia, inicia de inmediato el texto enfático de la Introducción: "¡Sombra terrible de Facundo!...". La publicación continúa durante ese mes y el siguiente. Alternan con el folletín furibundos ataques en respuesta a los periodistas chilenos que lo llaman "chancleta, ranchero, sargento Pino, necio, botarate..." (así el Rebujón de El siglo). 
Las circunstancias en que nace el Facundo son, como vemos, poco favorables para la expresión meditada y pulcra. Este pecado de improvisación lo irá pagando a lo largo de su siglo y del siguiente, sometido como ha de estar a reimpresiones y traducciones no siempre más cuidadas que la edición originaria.

Se ha repetido hasta en Palcos, autor de la excelente edición crítica de la Universidad de La Plata, que la primera versión en libro del Facundo repite el folletín de El Progreso. La misma afirmación se halla en el editor de las notas de Alsina. No es así, totalmente: Sarmiento hizo correciones de forma a la hoja del diario, y de estructura interna, como se verá. En cuanto al folletín en sí, agreguemos que desde el 2 I de julio, fecha en que el diario cambia de formato, el Facundo comienza a publicarse en suplemento aparte. Un anuncio del 6 de aquel mes dice a los lectores de El Progreso: "El Facundo no entrará en la nueva edición del Diario por los embarazos que causaria a los que quieren conservarlo, el tenerlo en dos pliegos distintos. Sabiendo que no quedan sino dos o tres capítulos por publicar, los daremos en suplementos del tamaño de los números anteriores a esta fecha" (diario citado, No 8 I3). Cuatto columnas de letra menuda, como todo el folletín y la primera edición que aprovecha la composición por razones de economía. La distribución de la materia es ya la del libro que aparecerá en julio: 2 partes distribuidas en capítulos con numeración propia: I a IV; I a XI.

Una confrontación total de la edición príncipe con el folletín no he podido cumplirla. No se encuentra en Buenos Aires una colección que reúna los números de mayo y junio del diario chileno. Quede señalada, hasta que se cumpla la necesaria compulsa, esta diferencia: la edición primera (II parte, Cap. IX, Barranco Yaco!!!) agregaba a continuación del párrafo que comienza en "Facundo, demasiado penetrante...", el párrafo iniciado así: "Creo oportuno hacer sensible, etc.,". El agregado incluye el párrafo que empieza: "Ferré en estos procedimientos", etc, hasta terminar.

\section{LA AVENTURA DE UNA CIFRA}

Indice de la general fluctuación en que se mantiene el Facundo a través de las ediciones que más importan, es lo ocurrido con un párrafo del mismo capítulo IX de la 2da. parte. Sirve asimismo para puntualizar una vez más, diferencias muy evidentes entre el primitivo folletín y las ediciones siguientes. En el trozo que muestro se mantiene la diagramación 
original para que se vea mejor la naturaleza del cambio introducido; dice el folletín:

...el año 1830 el ieneral Madrid se apoderó de un tesoto de treinta mil pesos pertenecientes a Qiroga i mui luego fue denunciado otro de qince. El escribia despues aciéndole cargo de noventa i tres mil pesos, qe segun su dicho contenia aqellos... ( $\mathrm{N}^{\circ} 813$, foll. de El Progreso, 3ra. col.).

El texto de la Ira. edición difiere de éste. Sarmiento necesita - es evidente- poner "Quiroga" en lugar de "él", para aclarar el texto y la cifra cambia sin duda para no prolongar la "recorrida" de las líneas siguientes. Esto origina un cambio de forma, correlativo: la cantidad pasa a cifra numérica pero con el error que puede observarse:

- . año 1830 el jeneral Madrid se apoderó de un tesoro de treinta mil pesos pertenecientes a Qiroga, i mui luego fue denunciado otro de qince. Qiroga le escribio despues aciéndole cargo de 39 mil pesos, qe segun su dicho, contenian aqellos... (1ra., p. 238).

Sarmiento observa el error y lo salva en la "Fe de erratas" agregada al final. Muchos otros errores tipográficos que se encontraban ya en el folletín, subsisten en la xra. edición y originarán la advertencia que el tomito muestra al final del texto. Pero aquella errata salvada por Sarmiento no es atendida en las ediciones 2da., 3ra. y 4 ta. Persiste en ellas "39 mil pesos". La edición de las obras completas (T. VII) que, como veremos, desatiende el mayor número de cambios introducidos por Sarmiento, nos da una cifra nueva: "59 mil pesos" (p. I70, I.23). Palcos, en la edición citada, corrige definitivamente.

Pero no todos son errores en la modesta página de El Progreso. No faltan a partir de la primera, aunque no este caso, ultracorrecciones que engañaron al mismo Palcos. En el folletín (Cap. IX, Barranca-Yaco, 2 da. columna) y en párrafo que empieza "Las conquista de Facundo abian tomado...", leemos: "El nombre de Facundo llenaba el vacío qe las leyes, la libertad i el espíritu de la ciudad abían dejado, i los caudillos de provincia...".

La edición primera repite el texto. También en la 2da. (p. 236). La edición de 1868 (3ra.) y la 4 ta. (que es reproducción casi textual de la última) introducen una variante que afecta al recto sentido de la frase, compuesta ahora con la suma de palabras nuevas y diferente puntuación. Leemos:" El nombre de Facundo llenaba el vacio de las leyes; la libertad i el espíritu de ciudad habían dejado de existir; i los caudillos de provincia..." (3ra. y 4ta. ed. 152). 
La edición de la Universidad de La Plata (1938) reproduce el texto

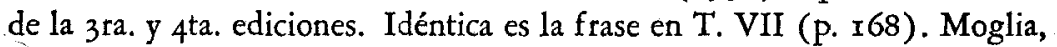
en edición Peuser (1955) restituye a la frase la forma original. (c. XIII, p. 177).

\section{LA PRIMERA EDICIÓN: I845}

El pequeño volumen, en $16^{\circ}$, tiene 324 páginas. La pieza 20.784 de la Biblioteca Nacional, que consulto, tiene una dedicatoria de Sarmiento a Florencio Varela, quien en ese mismo año entregaba, en folletín a $E l \mathrm{Na}$ cional de Montevideo, los primeros capítulos del Facundo. Comenzó en el número 2,04I del 3 de octubre de I845 y quedó interrumpido el 6 le febrero de 1846. Un anuncio del 4 de aquel mes se refiere a él: "Ayer - dice-principiamos a insertar en el folletín -como lo había prometido El Nacional- la vida del general Quiroga. Este escrito pertenece a un género de estudios de que está menesterosa la prensa americana". Después, el 6 de octubre, el mismo diario, previendo posibles controversias, declara que "no aceptamos ni repudiamos los pensamientos ni los hechos de este escrito..." (ed. Palcos, p. 470). Este folletín aparece bajo el título general de "Estudios americanos". Pero veamos ya la primera edición. En la portada se lee: "Civilización i Barbarie / Vida de / Juan Facundo Qiroga / I aspecto fisico, costumbres i abitos de la RePÚbuica Argentina / on ne tue point les ideés, Fortoul / a los ombres se degüella: a las ideas no. / por / Domingo F. Sarmiento / miembro de la Universidad de Chile i Director de la Escuela Normal / Santiago / Imprenta del Progreso / 1845". Una advertencia del autor en la primera página procura la justificación de errores dentro de un trabajo "echo de prisa, lejos del teatro de los acontecimientos". Nos informa sobre las fuentes; el libro se ha escrito "consultando un testigo ocular sobre un punto, registrando manuscritos formados a la ligera o apelando a las propias reminiscencias". Esta nota queda suprimida en ediciones sucesivas hasta la 4ta. (1874). La edición de O. C. también la incluye. El crítico de las notas de Alsina escribe, pues, erróneamente: "El editor introduce una página de advertencia (se refiere al $t$. VII) que no existe en la edición de 1845 de Chile ni en la de 1868 de N. York, ni en la de París de I874. Aquella página está sin embargo datada en I845". (Revista de Derecho, Historia y Letras, Buenos Aires, I90r, año IV, T. X).

En la página siguiente, bajo el epígrafe de Fortoul hallamos las palabras que explican cómo "desterrado por lástima, estropeado, lleno de cardenales, puntazos i golpes..." escribió al pasar por los baños de Zonda 
la frase predilecta y qué significado profundo debía alcanzar en su vida futura. La invocación a Facundo se coloca en página 5 , bajo el título Juan Facundo Qiroga. Y a la derecha el epígrafe de Villemain: "Je demande...", que traduce una muy caprichosa concepción de la historia, acorde con el tono combativo y "l'amour de la liberté" del polémico Sarmiento. El texto, of rece una particularidad en la paginación: entre las que llevan número 242-243 se colocó una página sin folio. Se mantiene la distribución en partes: la ira. (Aspecto físico de la República Argentina, i caracteres, etc.), se distribuye en cuatro capítulos a partir de la página I9. La 2da. parte (Vida de Juan Facundo Qiroga) consta de I I capitulos. La palabra "Finis" en el centro de una viñeta alegórica, cierra la última página. Sarmiento, sin disimular la irritación que le produce el cúmulo de errores que comprueba, coloca al final una "Fe de erratas" precedida por estas palabras: "La multitud de errores tipográficos de qe por circunstancias inevitables a salido plagada esta edición ace embarazosa la formacion de una fe de erratas exacta. Se an anotado por tanto solo aquellas faltas qe adulteran el sentido i qe la sagacidad del lector no podria rectificar". Y en cuanto a los errores de fondo, la observación prometía salvarlos ya libre de preocupaciones "qe an precipitado la redacción de esta obrita... apoyándola en numerosos documentos oficiales". El número de errores salvados y la calidad de las faltas dicen por sí mismos del descuido tipográfico con que la obra fue impresa. Así leemos "materiales" por "matorrales" (p. 5I, I.I7); "Virreino", por "Virreinato" (p. I39, I.27); "faistórica" por "faz istórica" (p. I23, I.20); "colcarse" por Balcarce; "Emprende audaza" por "emprendedora" (p. I35, r.27?); "del orro a la gara" (sic) por "del zorro a la garza?" (p. 20I, r.6).

El lenguaje de Sarmiento registra aspectos curiosos. Algunos pequeños pasajes ilustrarán, sin más, sobre la ortografía de este momento chileno que suprime la " $h$ " muda, la " $y$ ", los acentos agudos y hasta los graves ("aria" por "haria"), la "u" después de "q" (qe, qienes) y reemplaza la "g" fuerte por " $j$ " y la "v" por la "b" ("belluda'). Leemos: "Yo qe ago profesion oi de la enseñanza primaria, qe e estudiado la materia" (c. IV, p. 63); o "... porqe ace onor a Qiroga..." (II, 4I3); o "Qé mella aria la revolución de I8Io?..." (III, 2da. parte, p. I29).

\section{LA SEGUNDA EDICIÓN: I85T}

Se imprime también en Santiago de Chile. El año anterior ha publicado Sarmiento su Arjirópolis y en la portada reemplaza su nombre por 
el del libro que ha hecho crecer su fama de escritor. La portada reza: "VIDA DE Facundo QIRoga / I aspecto fisico, costumbres y hábitos de la República Argentina / seguido de / Apuntes Biográficos / sobre el jeneral Frai Feliz Aldao / por / El Autor de Arjirópolis / Sefunda edición / seguida de un exámen critico traducido de la Revista de Ambos Mundos / Santiago / Imprenta de Julio Belín i Compañia / i85r".

Las 304 páginas se distribuyen ahora en 13 capítulos sin división en partes. Sorprende de inmediato la amputación de los dos últimos capítulos y la "Introducción". Por error se enumeran los capítulos de I a XIV; falta la asignación del capítulo VI y así el que lleva como título "La Rioja" (II de 2da. parte en Ira. edición) se coloca bajo el número VII.

Las circunstancias políticas han variado. Sarmiento se anticipa a la caída de Rosas y procura suavizar el áspero tono de panfleto con que tradujo su afán bélico en I845. Además ha influído fuertemente la lectura cuidadosa que su amigo el Dr. Alsina viene haciendo desde años atrás, lectura que dio el fruto de $5 \mathrm{I}$ notas abundantes, prolijas y severas. La carta-prólogo con que dedica el libro a su amigo es de mucho interés. Insiste Sarmiento aquí sobre la inspiración espontánea que originó la obra y sobre "los muchos lunares que afeaban la primera edición". En cuanto a sus notas le advierte que las "ha usado con parsimonia... guardando las mas substanciales para tiempos mejores $i$ mas meditados trabajos, temeroso de que por retocar obra tan informe, desapareciese su fisonomia primitiva i la lozana i voluntariosa audacia de la mal disciplinada concepcion". Explica la supresión de los dos capítulos finales "ociosos hoi recordando una indicación de Vd. en 1846 en Montevideo en que me insinuaba que el libro estaba terminado con la muerte de Qiroga". En cuanto a la Introducción dice que la ha considerado "inútil". Tal vez debió decir "inoportuna".

\section{LAS NOTAS DE ALSINA}

Llegaron manuscritas a Sarmiento. Así las utilizó él. Augusto Belin Sarmiento, nieto del prócer, las entregó para su publicación a la Revista de Derecho, Historia y Letras. (Véase Año IV, I90I, t. X y XI). El crítico que las da a conocer afirma haberlas confrontado con las ediciones de $1845, I 868$ y 1874 a fin de consignar la atención que Sarmiento les prestó. La tarea resulta en gran parte ineficaz porque, como también observó Palcos, no tuvo en cuenta la edición de $185 \mathrm{r}$, que es donde precisamente se consigna el mayor número de ellas. $\mathrm{Al}$ estudiar las ediciones sucesivas se verá esto con más claridad. 
Las notas de Alsina apuntan particularmente a los hechos históricos. La faz literaria sólo es señalada como perjudicial. Así observa a Sarmiento en la nota 2: "creo entrever un defecto general; el de la exageración". Y añade: ... "tiene mucha poesía, sino en las ideas, al menos en los modos de locución". Estas notas retratan al unitario rivadaviano que era Alsina, pero también al hombre de agudo poder de observación, sagaz, atento y de lúcida memoria.

Del balance surge que Sarmiento atendió a no más de la mitad de estas observaciones que sumaban 5I. Señalemos de paso que algunas (Nos. $\mathrm{r} 7,28,38,40 \mathrm{y} 48$ ) son acotaciones o formas de asentimiento como cuando Alsina responde "Esto es cierto" a las palabras "Me ha batido en regla" (nota 40). Otras veces (nota I $7 a$ ) Alsina, que parece había negado la batalla de La Tablada, vio cómo se aludía a él en las palabras de la página 149 (Ira. edición): "Un unitario no cree en el triunfo". Alsina contesta sobriamente: "Al menos cuanto a lo pasado de I83T a r84 I, esto es ciertísimo por lo que he observado en otros y en mí mismo. Después creo haber curado de esa manía y estar en guardia contra su repetición". Estas notas beneficiaron al Facundo en la medida en que fueron atendidas. $\mathrm{Y}$ el libro, una vez reintegrados la Introducción y los dos capítulos finales (recién en la edición subsiguiente de 1874) mostró que habia ganado en sobriedad y verosimilitud sin que sufriera "la voluntariosa audacia" de que hablaba Sarmiento. Entre las no atendidas quedan observaciones válidas y muy interesantes. Así la que se refiere a los tipos pampeanos. "Vd --escribe Alsina- hace de esos caracteres excepcionales, una especie de clase y esto es lo que creo no es exacto". (nota 2).

Señalo algunos excesos que Alsina rechaza. Sarmiento escribe refiriéndose a Córdoba: "La Universidad es un claustro en que todos llevan zotanas i manteos" (Ira., p. I37). Alsina protesta: él no ha visto jamás sotanas ni manteos". Y Sarmiento corrige: "Los colegios son claustros . . ." (2da., I38). En la pág. 67 de la rra. edición, decía: "Eran otros tantos bandidos comandantes". La $2 \mathrm{da}$. elimina "bandidos" (2da., 62). También con referencia a Córdoba escribía Sarmiento en la edición de I845: ". . cúpulas i torres de los muchos templos". Alsina afirma, siempre fríamente objetivo, que él no ha visto más que siete. Sarmiento acepta y suprime el párrafo. ( Ia., I 28; 2da., I39). Siempre en defensa de Córdoba, como después en favor de Buenos Aires, Alsina protesta cuando lee: "(Córdoba) ... que no ha tomado parte en la revolución...". Sarmiento elimina la frase ofensiva. (Ira. II30; 2da., I4I).

Buenos Aires ha sido objeto de violentas inculpaciones. Alsina asu- 
me su defensa cuando Sarmiento pone a Robespierre y La Convención como modelos revolucionarios. "Jamás - replica Alsina - un pueblo hizo una revolución tan grande con menos violencia". Y Sarmiento tacha "Robespierre y la Convención, los modelos" (Ira., I3I; 2da., I42).

Desde el folletín de El Progreso el lector lee aquello de "Facundo... aunque enemigo de la Presidencia...". Alsina lo insta a corregir. Y las ediciones sucesivas reemplazan "Presidencia" por "unitarios", con más propiedad. El párrafo queda así mal construído (véase Ira., I64; 2da., I84)., como observa Palcos, pero se ha ganado en precisión. Hay párrafos enteros eliminados de la rra. edición. Así el que empieza: "Al gran pueblo argentino, Salud!" Alsina le ha hecho notar un error de cronología que Sarmiento salva suprimiendo el trozo. (Ira., I34; 2da., I46). Pero lo testado vuelve a la edición del t. VII (p. roo, I.I5 y sig.). A raíz de la nota $4^{2}$, Sarmiento reconstruye lo referente a los sucesos de Río IV y Río V, que la primera edición trae en pág. r97-98 y la segunda en 226-27. Raúl Moglia observa (nota a p. I5I, I.I7 ed. Peuser, I955) que Sarmiento "no dice que la acción de Río $V$ sea anterior a la de Río IV". Una anécdota vinculada a Facundo en Buenos Aires sufre cambios motivados por la nota 47 de Alsina. (Cfr. rra. edición-hoja sin numerarpárrafo que empieza en "La policía persigue a un bandido..." con el correspondiente en ed. 2a., p. 286). Y hay además otros muchos cambios motivados por las notas No 43 (ra., r99; 2da., 227); 46 (ra., 239; 2da., I77.8); 49 (ra., 244; 2da., 288). Alsina consigna al final: "He omitido... varias pequeñeces, pues sería de nunca acabar..." con lo cual nos deja entrever que el libro contenía a su juicio, mucho más para revisar. Sarmiento, por su parte, transmite en una nota, que agrega al final del capítulo VIII - Sociabilidad-Ia Rioja (p. I56), su gratitud al crítico severo: "He debido - escribe-a la amistosa franqueza del Dr. Alsina, rectificaciones sobre este $\mathrm{i}$ varios puntos que en honor suyo $\mathrm{i}$ como atenuación, someto al exámen del lector, dando así la reparación posible, sin destruir el espíritu del testo original". Se refiere aquí en particular a la pintura de Córdoba y de inmediato reproduce en su casi totalidad la nota 2 de Alsina ya citada, que incide sobre aquel "defecto capital"; el de la exageración.

Al margen de las modificaciones suscitadas por Alsina, Sarmiento revisó y corrigió por sí mismo, muchos pasajes cumpliendo así con aquella vieja esperanza expresada en la "Advertencia" de la primera edición. Muchas notas (apoyadas algunas en reflexiones de Alsina (como la de n' 30 citada en p. 143) aclaran conceptos o amplían una idea. Como su- 
prime parte del texto en páginas $83-86$ de la primera edición agrega una nota (2da., ed., 84) que se refiere a la escuela de San Juan: "Detalles sobre el sistema... se encuentra en Educación Popular". (véase p. 47 de 3 ra. y 4 ta. ediciones). A completar referencias históricas tienden otras notas como la que amplió la de p. Io6 (2da. edición). Pero el mayor número busca atemperar los ataques contra Rosas, Buenos Aires, el Clero, Rivadavia o los unitarios. Veamos:

Estoy seguro de que el alma de cada unitario degollado por Rosas a abandonado el cuerpo desdeñando al verdugo qe lo asesina $i$ aun sin creer qe la cosa a sucedido" (2da., 149 elimina el párrafo de 1a., 137). Otro: a continuación de "sicarios" (1a., 217, 18): "Mañana saldrán por las calles, gritarán Viva la Federación! en todas las esquinas; mueran los salvajes unitarios! Después entraran en las casas de (aqí viene la lista) i los degollaran. Les cortaran la caheza i las apilaran en el mercado; los carros de la policia an recibido orden de recojer los cadaveres $i$ seguir la procesion por toda la ciudad. No descuide acer gritar en todas las esqinas, etc." En Europa no saben nada con respecto al orden minucioso qe. puede poner en la administracion un jenio prolijo, qe no descuida nada, qe todo lo prevee, qe todo lo advierte!

Trozo de franca entonación patética, hace ganar una vez suprimido, calidad estética al párrafo con que cierra el capítulo XII (2da., 250). Y véase el siguiente no menos cargado de énfasis dramático:

...La madre de d. Juan Manuel Rosas se a echo servir de rodillas por sus criados asta sus últimos dias; nunca se presentó en su presencia sirviente alguno de pie derecho: ai teneis la educacion del ijo, ai toda la istoria de su gobierno.

Estas líneas se hallaban en la ra. edición (p. 230) y no aparecen en la $2 a$. (265). Otro caso de supresión es el que se descubre comparando el pasaje que empieza en $2 \mathrm{da}$., 254, en las palabras "La consternación..." con el de xra., p. 22x: "...por qe el enviado DE DiOs..." hasta presbítero Colombres. Estos y otros momentos (cfr. xra. y 2da. ,p. I55, 2r3, 2r 4 y $2 r_{5} \operatorname{con} 17 \mathrm{I}, 245,246$ y 247 respectivamente) que mostraban una idéntica exacerbación melodramática en las acometidas contra Rosas o Quiroga, quedaron fuera de las ediciones sucesivas hasta la de 1874 inclusive. Como veremos, la del $\mathrm{T}$. VII de $\mathrm{O}$. C. restituye al texto muchos de estos trozos cercenados.

Otras enmiendas, procuran un mayor ajuste designativo: "criminales vulgares" pierde el adjetivo ( Ira., 98; 2a., 99); "momento grande y espec. 
table pasa a "momento grande y digno" (Ira., II4; 2a., II3); "Facundo asta aqi es como todos, como Rosas", se convierte en "Facundo hasta aqi es como Rosas" (Ia., I2I; 2a., I 30). La siguiente denota una sutil distinción de matices que podían afectar al elevado concepto en que deseaba mantener al general Paz. "Poco esfuerzo de penetración costó al jeneral Paz..." se lee como "Poco esfuerzo de penetración costó al jeneral Paz" (Ia., I9I; 2a., I8); "Porque el mineral de Uspallata es un cadaver" (Ia., 204) desaparece de la página 234 en la 2da.; "bandidos de la campaña" (Ia., 209) pasa a ser "jefes de la campaña" (2a., 24I); el "levántate, vengo a matarte" ( Ia., 2II) pasa a 2da. como: "Levántate!" (p. 243). Aunque con apariencia de significar todo lo contrario para el lector desprevenido, la palabra "vomitivo" (Ira., 259) se convierte en "elixir" (2da., p. 302); "siete millones de moreras" (Ira., p. 205) se modera en "algunos millones de moreras" (2da., 235) como "diez mil estancias" (Ira., 55), queda en "mil estancias" (2da., 47), por la nota 2 de Alsina.

En la imposibilidad de agrupar sin fatiga todas las modificaciones introducidas en la 2da. edición, remito al lector al Facundo ya citado, que anotó con muy pequeños errores u omisiones Alberto Palcos (edición de la Universidad de La Plata, I938) y al trabajo, no menos feliz en sutiles hallazgos, de Raúl Moglia. Ellos han servido de guía para la confrontación que he efectuado, de las cuatro primeras ediciones en castellano y la menos fiel de las Obras Completas (I889).

En esta edición de I85 I el idioma de Sarmiento registra algunas variantes que lo acercan al castellano usual. Algunas formas: "vihuela" (2da., 35), por "viuela" (Ira., 46); "huertos" (2da., 39) por "uertos" ( rra., 48), "ácia" se convierte en "hácia"; formas como "qe" y "qeda" recuperan la "u' intermedia.

Por último, como ejemplo tanto de lenguaje como de modificaciones que no aciertan a mejorar el texto sino más bien a aumentar la confusión de la frase, véanse los dos trozos siguientes que corresponden a un mismo pasaje:

1ra., pág. 173:

Estas enormes masas de jinetes qe van a revolcarse sobre los ochocientos veteranos, tienen qe volver atras a cada minuto $i$ volver a cargar para ser rechazados de nuevo. En vano la terrible lanza de Qiroga ace la retaguardia de los suyos tanto estrago como el cañon: la espada de Ituzaingo acen al frente. Inutil! Son las olas de una mar embravecida qe vienen a estrellarse en vano contra la inmovil i áspera roca. 
2da., pág. 195:

Aquellas enormes masas de jinetes que van a revolcarse sobre los ochocientos veteranos tiene qe volver atras a cada minuto $i$ volver a cargar para ser rechazados de nuevo. En vano la terrible lanza de Qiroga hace en la retaguardia de los suyos tanto estrago como el cañon i la lanza de Ituzaingo hacen al frente. Inutil! En vano remolinean los caballos al frente de las bayo. netas $i$ en la boca de los cañones. Inutil! Son las olas de una mar embravecida que vienen a estrellarse contra la inmovil i áspera roca.

TERCERA EDICIÓN: I868

En la portada se lee: "FACUNDO / CIVILIZACIÓN I BARBARIE / EN / IAS PAMPAS ARJENTINAS / por / DOMINGo F. SARMIENto / Cuarta edición en castellano / Nueva York: / D. Appleton y Compañía / 90, 92 y 94 Grand Street / I868.

Se trata, a pesar de lo indicado en la portada, de la 3 ra. edición en castellano. Sarmiento se halla en los Estados Unidos como ministro enviado por el gobierno argentino. La ordenación en capítulos sigue, lo mismo que el texto, la 2 da. edición con algunas variantes que enseguida veremos. Igual que en el libro de I85 I faltan en éste la Introducción y los dos capítulos finales. "La causa es adivinable-escribe Palcos-. La edición aparece el año de las elecciones presidenciales en la Argentina, como medio de prestigiar la candidatura del autor, apoyada por el Partido Autonomista, cuyo jefe, Adolfo Alsina integra el binomio triunfante'. El partido de referencia apoya en Sarmiento las ideas que se oponen a la capitalización de Buenos Aires, y es precisamente en las partes suprimidas del libro donde "defiende - continúa Palcos- la tesis de que Buenos Aires es la única capital posible del pais. (Ed. cit. prólogo p. XIX-XX). No se incluye tampoco la carta-prólogo al Dr. Alsina que apareció en la 2 da. ni las notas de Sarmiento que en la edición de I85 I hacían referencia o transcribían observaciones del celoso lector. Subsisten sin embargo los cambios introducidos en la composición de la anterior. El material del volumen se distribuye como sigue: a) Prefacio de la traducción inglesa, escrito por Mrs. Mann. [véase "Traducciones"]; b) Cuerpo de la obra: "Civilización i Barbarie". Cap. I a XIV; c) Apéndice: documentos de Quiroga; d) Aldao; c) El Chaco.

Algunas diferencias formales se deben a la corrección de pruebas, que según el mismo Sarmiento, realizó a su pedido el gramático cubano Mantilla "hallando poco que corregir de las anteriores, llamándole la atención la ocurrencia (sic) frecuente de locuciones anticuadas pero castizas que 
atribuía a muchas lecturas de autores castellanos antiguos". (Carta al prof. D. Matías Calandrelli, en O. C., T. VII, p. IV).

Don Luis Montt, a cuyo cargo estuvo la edición de I889, puso una nota al pie de esta carta en la que afirma, a propósito de lo aseverado por Sarmiento: "Es decir, corrigió las pruebas ("edición" escribía Sarmiento) de la edición de 1868 pues al hacer esta reimpresión i comparar esa edición con la de 1845 no hemos encontrado otras diferencias que las que resultan de la mejor corrección de pruebas. El Editor'". Esta ingenua apreciación confundió aún al editor de las notas de Alsina (véase p. I I I en t. y rev. cit.), que puntualiza también otras variantes ortográficas, olvidando lo fundamental: esas notas de la 2da. edición que él mismo publica por primera vez y comenta con relativa amplitud aunque descuidadamente. La confusión persiste en las ediciones posteriores que toman el comentario de Montt al pie de la letra. Palcos deploraría después, que un juicio tan inexacto se halle en la edición de las obras completas y haya "merecido plena fe a cuantos lo reprodujeron posteriormente" (Facundo, ed. cit., nota a pág: 455). La irritación del crítico es todavía mayor cuando a esas palabras y al texto del T. VII se refiere en su libro Facundo, rasgos de Sarmiento, cuya primera edición es de r934 [véase op. cit., Leviatán, 1945, pág. 87].

Como arriba se indica, a este Facundo de 1868 se agrega la biografía de Aldao ( $r$ ra. edición, sin portada ni descripción, aparecida en I845 y compuesta con el folletín de El Progreso) y la de Peñaloza (El Chacho, último caudillo de la Montonera de Los Llanos, episodio de I863), recién termianda en los Estados Unidos, donde se halla. Palcos atribuye, con buen criterio, un fudamento político a esa inclusión última. El librito se proponía - dice- "elogiar las virtudes de un gobierno fuerte y anticaudillista, que era lo que el país, a la sazón, andaba necesitando". (Ibid., pág. 94).

Como al quitarle los dos últimos capítulos el libro podía parecer inacabado, Sarmiento agregó bajo el último capítulo de "Barranca Yaco" (c. XIII y final) el trozo que comienza: "El gobernador de Buenos Aires, etc...." y termina en "... instigador de los asesinos" con que se cierra la obra en esta edición.

Observemos algunos cambios de forma no siempre felices. En ira. y 2 da. edición se leía: "...si bien se hacía intolerable". En la 3a. y $4^{\text {ta. }}$ (p. 69) dice: "... si bien su recaudación se hacia intolerable". Esta edición agrega lo subrayado en el trozo, siguiente: "La fe os salvará i en vos confía la civilización", que falta en las anteriores (Ira., p. I75; 2da., p. r98), por más que, como afirma Palcos (nota 8I bis), "el pensamiento 
se enturbie manifiestamente". El párrafo que en la Ira. edición comenzaba: "Estas enormes masas, etc.," se construye de nuevo con mayor claridad, en la 2 da. (p. I95); pero en la de I868 (p. I08) registra errores que repite la de 1874 (p. I08). La versión de Palcos devuelve al párrafo su construcción correcta, según la de i85 I. Igual la de Moglia (IX, I3I). Otros cambios que atañen a la corrección sintáctica o designativa de personas y lugares, se hallan recogidas por este último en "Variantes de ediciones" (Ed. Peuser, I952).

\section{CuARTA EDICIÓN: I874 (EN CASTELlaNo)}

Las circunstancias en que se da esta edición están definidas en una cartá que Sarmiento dirigió a su nieto, Augusto Belín Sarmiento, que se hallaba entonces en París, poco antes de terminar su presidencia. "Interesa mucho a mi política - le dice muy confidencialmente en marzo de aquel año-y convendrá más al editor de la $4^{\text {ta. }}$ edición de Civilización y Barbarie, que los ejemplares lleguen aqui antes de terminado mi gobierno. Para ello - continúa - no debe perderse tiempo, empezando a componer la introducción y dos capítulos finales de la ira. edición sobre el formato de la 3 ra. y la Vida de Aldao y Carta a Alsina de la 2da. con los demás accesorios de la edición francesa e inglesa que juzguen convenientes". La carta - "muy reservada" según el mismo Sarmiento- contiene conceptos interesantes de autocrítica sobre el libro al que llama "especie de poema, panfleto, historia". En la nueva edición constituitá "un libro voluminoso y casi nuevo - escribe - porque nádie ha leído todos esos documentos reunidos".

Se lee en la cubierta: "FAcundo / o / CivilizaCión I BARBARIE / EN las pampas argentinas / por / Domingo F. SARMiento / Cuarta edición en Castellano / París / Librería Hachette y Cía. / 79 Boulevard Saint German 79/I874".

Restablecida la Introducción, vuelven también la carta a Valentín Alsina y los dos capítulos finales. El texto, diagramación y distribución en capítulos responden a la 3 ra. edición. Falta entre páginas 48 y 49 el grabado de Quiroga que la $2 \mathrm{da}$. incluía. La única ilustración es un excelente dibujo a pluma del propio Sarmiento, realizado por L. Massard. Las $37^{\circ}$ páginas del texto se distribuyen en 15 capítulos. Por error el capítulo; IX se lo designa como XI. No obstante la corrección de orden tipográfico, registra avances con respecto a la edición anterior. Persiste sin embargo algún trozo obscuro como el que cierra el capítulo VI (La Rioja) : 
En esos llanos donde ahora veinte años pacian tantos millares de rebaños vaga tranquilo el tigre que ha reconquistado su dominio, algunas familias de pordioseros recogen algarrobo para mantenerse (c.c.p. 74).

Las ediciones de Palcos y Moglia (p. xI9 y p. 95 resp.), vuelven al texto de 185 I que a su vez modificaba la versión primitiva de I845, suprimiendo después de "dominio ("dominios" en r ra.), lo siguiente: "El Chacho es el hombre más distinguido que posee La Rioja i oi acepta del gobierno de San Juan la Comandancia de un escuadrón para vivir" (p. I22, ed. cit.). La otrografía desconoce aún la " $y$ " conjunción o consonante pero la " $h$ " muda se ha restituido desde la edición anterior. Leemos: ". . i es lei de la humanidad" (Intr. XXV, I.28). La acentuación sigue siendo caprichosa ántes, educacion, apénas, leido, creido, pais. La " $g$ " fuerte no se emplea: "frájil", "jeneral", "orijen".

Lo observado acerca de la página 108 de la edición anterior es válido también para ésta. El párrafo que comienza "El gobierno de Buenos Aires...", agregado ya al capítulo XIII en la anterior al amputársele al libro los dos últimos capítulos, permanece en ésta no obstante habérsele reintegrado de acuerdo a la $x$ ra.

Esta de 1874 es la última edición tirada en vida de Sarmiento.

QUINTA EDICIÓN: I888-I889

Casi desconocida, tiene el interés de ser la primera impresión ríoplatense del Facundo. Concebida con sentido de difusión popular por don José Battle y Ordóñez en Montevideo, formó parte de un interrumpido plan cuyo primer tomo fue una antología de poetas. Los tres siguientes integraron el Facundo y allí se quebró el sano propósito editorialista de Battle y Ordóñez, que quiso realizar, quince años antes que La Nación de Buenos Aires, el ideal de una biblioteca popular para los lectores del Río de la Plata. En un artículo de El Dia de Montevideo (ro de junio de I903) se recuerda aquel intento en relación con el más fructífero del diario argentino.

Es curiosa la cubierta: sobre un fondo que dibuja la bahía de Montevideo y el teatro Solís, se destaca una alegoría de la ciencia; al centro y debajo de "Biblioteca Latino-Americana / colección de los mejores autores / T. II, / el título y autor. El primer tomito es de I888, pero los dos siguientes salen en 1889. Muchos descuidos tipográficos afean la 
edición, que parece seguir la de I874. El texto está distribuido en I5 capitulos: T. Iro., de I a IV; 2 do., IV (cont.) a XI; 3ro., XI a XV. La ortografía responde en general a la de ediciones anteriores: "qe" por "que"; "estremidad" por "extremidad"; "enjendra" por "engendra".

\section{SEXTA EDICIÓN: 1889 (EN Obras Completas, T. viI)}

Por ley nacional de 1884 , que firmaron Julio A. Roca, Presidente, y Eduardo Wilde, Ministro, se editaron los escritos de Sarmiento a partir de r887. El T. VII incluye el Facundo; la edición se puso al cuidado, como queda dicho, de don Luis Montt. El contenido se distribuye como sigle: a) Carta al profesor D. Matías Calandrelli; b) Advertencia del autor (tomada de la ed. de 1845); c) "On ne tue point les idees"; d) Introducción a la edición de $x 845$; e) Carta-Prólogo de la edición de I85 I (A V. Alsina); f) Texto: 3 partes divididas en capítulos; g) El jeneral Fray Felix Aldao; h) El Chacho.

Ya se ha visto el justo menosprecio en que tuvo Alberto Palcos esta edición. Puntualicemos algunos aspectos: El texto vuelve en general a la edición de 1845 . De la confrontación que según el editor, se ha cumplido con la edición de $x 868$, no ha resultado una depuración conforme a la realizada ya en el texto de $185 \mathrm{I}$ por el mismo Sarmiento a raíz de las notas de Alsina; éstas aparecen desatendidas en el mayor número. Ya vimos que el editor "no ha encontrado otra diferencia (entre la edición de 1845 y la de 1868 ) que la que resulta de la mejor corrección de pruebas". El editor no desconocía la de 1874 : al pie de la página $x 6$ leemos: "Ambos capítulos (se refiere a los dos últimos) los reproducimos en esta edición, así como lo fueron en la de París de r874.-El Editor". Lo atendido esencialmente puede concretarse a la eliminación de algunos trozos que desaparecen desde la edición de 185 r:

Irà. ed., p. $217 \cdot 218, T$. VII, p. 156 (después de "sicarios"): "Mañana saldrán por las calles, etc., ..." (eliminado desde 2 da. ed. en adelante).

Ira. ed., p. 22I, T. VII, p. I59 (después de "presbítero Colombres"): "...por qe el enviado de Dios no olvida nunca a sus servidores, etc., ..." (eliminado desde la 2 da. en adelante).

En cambio se restituyen al texto párrafos enteros susprimidos por Sarmiento; asi: 
Ira. ed., p. 2I3, T. VII, p. I53 (después de "dormitar un poco"): "El que lea esto, etc. ..." (falta desde 2 da. edición).

Ira. ed., p. 247, T. VII, p. I 54, 55 (después de "omitido"): "Os parece esto mucha degradación?" (falta desde 2 da. a 4 ta. ediciones).

Descontados los errores tipográficos, que son muchos (algunos en los epígrafes, arrastrados desde la ira. edición pero salvados en la 3 ra. y 4ta.), quedan numerosos lunares de construcción, de vocabulario y de puntuación. Uno de estos últimos cambia por completo el sentido de la frase afectada: la palabra "Montiel" (rra. ed. "Maciel", subsanada en fe de erratas) colocada entre comas (T. VII, p. I28) pasa a ser de topónimo, un nombre de gaucho (p.c.I.I3) : "... porque el gaucho, Montiel, no se atreve...". Las moreras vuelven a ser siete millones en esta edición (p. I48, I., ra.); los "jefes de campaña" regresan a "bandidos de campaña" (p. I5 I, I.2); los famosos 93 mil pesos, se convierten, como ya vimos, en " 59 mil pesos" (p. I70, I.23); en el párrafo que empieza en "De la acción de Chacón..." se agrega a la expresión "beberle la sangre" las palabras "como un salvaje" (p.c.I.24), por primera vez. La lectura de I cap. III ( $I^{\text {a }}$ parte) Sociabilidad-Córdoba-Buenos Aires) nos dará por fin la impresión cabal, confrontándolo con el correspondiente de ediciones que siguieron a la 2 da., del criterio que dominó en $D$. Luis Montt al cotejar las versiones que tuvo a su alcance. Retornan a estas páginas todas las supresiones y errores salvados que Sarmiento impuso al texto por virtud de las notas de Alsina o de propia inspiración.

\section{OTRAS EDICIONES EN CASTELLANO:}

Sólo se hace referencia aquí a algunas de ellas, curiosas o: importantes:

1889. Civilización y Barbarie-Vidas de Quiroga, Aldao i El Chacho/ Buenos Aires /F. Lajouane". Se trata de un volumen idéntico al del.t. VII de las Obras Completas, en cuanto al texto. La presentación tipográfica supera la de aquélla. Tiene frente a la portada un dibujo de Sarmiento hecho por Desmodry en 1854 . Son 74 páginas e índice.

r903. La Nación empieza a publicar en su "Biblioteca", el Facundo, del que saldrán, con ligetas diferencias de paginación, tres ediciones: 
más en I906, I909 y I9I7. Llevan un prólogo sin firma y siguen en defectos y virtudes, la edición del T. VII.

I9r5. A las ediciones argentinas se sumó en este año la de José Ingenieros para "La Cultura Argentina", con prólogo de Joaquín V. González.

I9I6. La preparó Ricardo Rojas para la "Biblioteca Argentina", que dirigía. Desdichadamente Rojas ignoró el problema que planteaban las diversas ediciones hasta la de 1874 . En la nota que puso al pie de la página II, se lee: "...me ha parecido que en este caso debía seguir el texto de las obras completas, que es el de la edición príncipe con la única variante de la ortografía que Sarmiento aceptó en vida..." Rojas, pues, acepta como bueno el criterio de D. Luis Montt y la palabra de D.A. Belin Sarmiento a la que aquí se refiere. Como la edición del T. VII, el texto aparece dividido en tres partes, de cuatro, nueve y dos capítulos, respectivamente. En un apéndice agrega $\mathrm{R}$. Rojas la carta al profesor Calandrelli, la advertencia del autor y la Introducción. Importa señalar, que aceptado este criterio de edición, el estudio que lo prologa es uno de los más bellos y precisos que la obra ha merecido.

Las ediciones del Facundo anteriores a I938 fueron superadas, con ilimitado margen, por la que produjo Alberto Palcos para la Universidad de La Plata, en ese año. Una erudición especializada hasta ahondar en las motivaciones profundas de cada pasaje y cada cambio, lo mismo que en la acumulación de circunstancias históricas, sociales, políticas e íntimas, concurrieron a la total comprensión de la obra. Realizó con pulcritud extrema la confrontación de ediciones y anotó con igual prolijidad el resultado de ese esfuerzo. Agregó a su versión-que es la de 1874 aunque integrada con todos los aportes señalados - importantes documentos, como son las notas de Alsina, juicios de periódicos y revistas, prefacios y cartas, reproducciones facsimilares y un prólogo esclarecedor. Libros como $\mathrm{Fa}$ cundo-rasgos de Sarmiento, y otros del mismo Palcos, son el auxilio indispensable que facilita al estudioso el acceso a las reales fuentes del creador.

Otra versión admirable es la que dio Raúl Moglia en la cuidada edición de Peuser, en 1955. En "criterio de la edición" expuso Moglia las fuentes que utilizó y el concepto que ha seguido para la modernización de la ortografía y la acentuación, que en la edición de Palcos queda atenida al original de 1874. En "Apéndices" sumó al texto las variantes de ediciones y agregó notas de aguda crítica. Reprodujo, en fin, ilustraciones 
preciosas, grabados, manuscritos, monedas, notas y piezas de mucho interés.

La "Biblioteca de Clásicos Argentinos", de Estrada, en su volumen II, publicó el Facundo, cuya 2da. edición consulto. Supera ésta a la primera, pues se apoya en las investigaciones que Palcos exhibe en la edición de la Universidad de La Plata. Inés Cárdenas de Monner Sans escribió un prólogo excelente que aclara la influencia de Fenimore Cooper sobre la exposición de los tipos pampeanos en Sarmiento. Delia S. Etcheverry, a quien pertenecen el texto y las notas, realizó una admirable labor para acercar al estudiante la comprensión del libro con notas históricas, geográficas y de léxico, en la más generosa amplitud informativa.

Recordemos, siquiera rápidamente, también por el esmero tipográfico y la penetración que emana de la nota preliminar de Pedro Henríquez Ureña, la edición Losada, Buenos Aires, I938. Y por último el esfuerzo que prestigiara a una entidad de nobles fines: la Sociedad de Bibliófilos Argentinos, que en 1935 entregó una lujosa edición, en gran formato y en el más pulcro cuidado tipográfico. Corregida por Palcos e ilustrada por Ángel Guido, redujo, con buen criterio, el material de las anteriores al texto y la introducción que precede la de 1845 .

\section{LAS TRADUCCIONES}

En una carta a Mrs. Mann, escrita en Nueva York el 4 de octubre de 1865 , Sarmiento trasmite a su gran amiga el placer con que acepta su propósito de traducir el Facundo al inglés y le recuerda que "sólo después que la Revista de Ambos Mundos lo anunció en Europa como una novedad y fue después traducido, se mostraton [en su país] maravillados de que fuese libro en efecto, eso mismo que por distracción habían leído". Se refiere también a la versión que A. Giraud realizó, "con notas como los escolistas de la edad media", para el editor Arthus Bertrand en 1853. Aquella traducción, en efecto, colmó de orgullo a Sarmiento y le abrió puertas a un interés nuevo en el público americano. Dividida en tres partes y sólo en 13 capítulos, pues se han eliminado en la edición de I85 $\mathrm{I}$, a la que se atiene, los dos últimos, incluye sin embargo la introducción, la carta a Alsina y las notas en el apéndice. También la ya conocida entonces biografía de Aldao, en un total de 343 páginas.

Una nueva versión francesa, de fina presentación, apareció en 1934. La realizó $M$. Bataillon para el Instituto Internacional de Cooperación Intelectual, con prefacio de Aníbal Ponce. Son 3 II páginas agrupadas por capítulos en tres partes, según la edición de las Obras Compietas. La 
crítica a la citada edición puede aplicarse a ésta. Una confrontación ligera nos permite descubrir todas aquellas partes y trozos que Sarmiento dio por eliminados desde la 2 da. edición. Por lo demás, la traducción es fiel y tipográficamente inobjetable.

\section{La traducción INGLESA de Mrs. ManN}

Como hemos visto, la edición en castellano de 1868 se hizo en Nueva York mientras Sarmiento representaba al gobierno argentino en los Estados Unidos. Esa edición contiene ya el prólogo que Mrs. Mann escribió al trasladar la obra al inglés. A propósito de la ira. traducción francesa me referí a la carta de Sarmiento a su amiga. Alli le dice también: "iQuien pueda traducirla sino quien mejor sabe sentir las ideas que ha querido expresar la introducción...!" Y continúa: "Sería este servicio muy importante para mí". Así encaró Mrs. Mann con seriedad obstinada y cálido afán comprensivo la tarea que abarcó al fin todo el libro y muchas otras páginas de Sarmiento, especialmente las que más le gustaban de "Recuerdos de Provincia". El libro incluyó pues el apéndice antológico de gran interés ("Biographical Sketch") y el Aldao en un grueso volumen de 396 páginas. En el notable prefacio escribió con palabras que implican una crítica justa: "Trataremos de dar estractos de éste [Recuerdos de Provincia], tan extensos como lo permita el reducido espacio de que disponemos, pues no pretendemos en esta breve compilación apropiarnos el título de biógrafos del coronel Sarmiento, tarea que sus compatriotas mismos no se imponen..." Toda la labor de Mrs. Mann trasmite la segura propiedad del espiritu que nutrió el libro, desde la introducción que la entusiasmaba. Cumplió magníficamente con las esperanzas de Sarmiento y sobre todo con lo que ella misma decía "del profundo interés que me inspiró la nación cuyas aspiraciones, más bien que su condición actual, él representa".

\section{OTRAS TRADUCCIONES}

Hay, como se sabe, otras traducciones. Entre ellas, una italiana de Fontana de Philipps (primero en folletín de La Patria Italiana, en I88I). Otra alemana, que incluye sólo las partes descriptivas, y otra, al mismo idioma, de Hans von Fran Kerberg (Edición de Argentinischen Wochen und Tageblattes, I9Ix). Se hizo bajo el título de Facundo Quiroga oder Zivilization und Barbarei. Es un volumen de rústica presentación. Sigue a la del T. VII de las Obras Completas y suma a las deficiencias, del origi- 
nal las propias de una interpretación descuidada en la forma y en el espíritu, según opiniones que merecen entera fe.

Queda así historiada, aunque con inevitables saltos, la aventura editorial del Facundo. Fue la suya una azarosa trayectoria. Nació proscripto, y aún más que su autor, viajó de uno a otro rincón de América y de Europa develando su alma por años y años, antes de hallar oídos en la propia patria. Mrs. Mann tuvo razón y también Alberto Palcos, cuando ya superada la etapa trashumante, pudo afirmar en I938:

El libro empieza a estudiarse serena y prolijamente, como que es el más representativo de nuestra literatura, el que mejor encarna los dolores, las batallas y los anhelos de la patria y constituye algo asi como la conciencia sufrida y lúcida de medio continente. ${ }^{1}$

\author{
Guillermo Ara, \\ Universidad de Buenos Aires.
}

1 Deseo hacer justicia a mis auxiliares. Dos ediciones, la de Alberto Palcos y la de Raúl Moglia, guiaron mi investigación. $Y$ dos bibliófilos de amplio espititu y generosa voluntad, D. Miguel Lermon (a cuya modestia pido perdón por mencionarlo aquí) y $\mathrm{D}$. Alberto Gowa, pusieron en mis manos las preciosas ediciones consultadas. A ellos, mi sincera gratitud. 